\title{
RISK AVERSION AND ATTRIBUTES OF STUDY ABROAD PROGRAMS AMONG MARKETING MAJORS IN THE U.S. AND NORWAY: VALIDATION OF CROSS-CULTURAL SCALES
}

\author{
Janice Payan, University of Northern Colorado, U.S.A. \\ Göran Svensson, Oslo School of Management, Norway \\ Nils Høgevold, Oslo School of Management, Norway
}

\begin{abstract}
Strong assertions have been made that study abroad students accrue important knowledge and intercultural competency that should enable them to succeed in an expanding global marketplace (Evans et al. 2008). Unfortunately, only 1 percent of U.S. students in two-year and four-year higher education programs are studying abroad during a single academic year - 273,996 out of the more than 20 million students enrolled in U.S. higher education (Institute of International Education 2012) and only $6.3 \%$ of all Norwegian higher education students studied abroad in 2002 (Statistic Norway: Education Statistics. Norwegian Students Abroad, 1 October 2002). The statistics from both countries indicate there is plenty of opportunity for a specific university to improve the participation rates of their own resident students studying abroad.
\end{abstract}

Targeting international students for short-term exchanges or study is also an opportunity. It is estimated that this year international exchanges in all 50 states contributed \$22.7 billion to the U.S. economy (Institute of International Education, 2012). Focusing on this opportunity can provide an opportunity for colleges to make up for decreasing enrollments (Adams, 2012), especially those public colleges that have been negatively impacted by government funding. Highlighting the opportunity to target international students, it is estimated that student mobility will nearly triple to eight million by 2025 (Wildavsky, 2010). Furthermore, by targeting more international students for short-term exchanges or short-term study in the U.S., the cultural diversity of the classroom will be enhanced academically, adding to the internationalization of the classroom.

A total of 326 questionnaires were obtained including 73 from a U.S. university and 252 from a university in Norway. The demographic profiles reveal some similarities and some differences between the groups. This study collects data from the U.S. and Norway because both countries are fairly comparable in per capita GDP and other economic variables, eliminating extraneous considerations.

Whether trying to improve resident student's participation in study abroad programs or trying to attract international students to study in another country, administrators can only be successful if they understand similarities and differences between cultures. An important aspect of this research involves testing the cross-cultural validity of the data collected from the U. S. and Norway to examine Risk Aversion (RISK), Motivators of Study Abroad (MSA), and three sets of deterrents of study abroad: 1. Economic Concerns (ECON), 2. Family Friends Work (FFW), and 3. Country Concerns (COUN) scales.

Findings suggest that these scales are valid in both different national contexts and can also be used to compare differences between the cultures. Adequate validity exists on the three scales (i.e., RISK, MSA, and COUN) for use in both the U.S. and Norway and the factor structure is equivalent between the groups. The loadings are very similar, suggesting full metric invariance to compare relationships between groups and the observed variable intercept terms are similar enough to compare construct means between groups with the exception of FFC. And finally the construct means for COUN is significantly lower in the Norwegian sample.

References available upon request 